\title{
Psychiatric advance directives: reconciling autonomy and non-consensual treatment
}

\author{
Adina Halpern and George Szmukler
}

\begin{abstract}
This paper examines the potential for advance cilrectives to be used by people with mental illness. Also known as a 'Ilving will, an advance directive encbles a competent person to make decisions about future treatment, anticipating a time when they moy become incompetent to make such decisions. In English low, if "clearly established" and "applicable to the circumstances", an advance directive assumes the same status as contemporaneous decisions made by a competent adult. A poychiatilic advance directive, onticlpating relapse of a poychosts, develops the concept of the llving will. We argue it could reconcile two cpparently contradictory themes in the current practice of peychlatiy - on the one hand, the call to provide for non-consensual treatment outside hospltal, and on the other, the promotion of patient autonomy.
\end{abstract}

Advance directives, also known as 'living wills', provide an opportunity to carry into an anticipated period of compromised autonomy in the future, decisions made while authors are autonomous. Their ethical basis is self-determination. They have been used in two ways: 'instructional', giving specific directions concerning treatments, and by designating a 'health care proxy' empowered to make decisions when the author's capacity is lost.

Under English law the unambiguous and informed advance refusals of competent adults are as valid and legally binding as their contemporaneous decisions, but advance consents are not legally enforceable as no one can require that medical treatment be given. Nor is it possible under English law to nominate another person to make legally binding treatment choices.

\section{A peychiatric advance directive}

To date, the debate around advance directives has focused on terminal illness situations and refusals of life-prolonging treatments. However, our view is that the concept of an advance directive should apply to other situations where capacity is predictably lost, including those which may be reversible. This is the case in some psychotic disorders, although it must be recognised that having a mental illness does not mean a patient is necessarily incompetent to make treatment decisions (Appelbaum \& Grisso, 1995). The PAD could potentially be used by patients with a psychotic illness causing a loss of capacity. Upon recovery of capacity, the patient could issue instructions concerning treatment if relapse with loss of capacity should occur again. For example, a patient may direct that at an early stage in relapse he should be given medication. even if he objects; or that he should be hospitalised against his will. This aspect of a PAD has been termed a 'Ulysses Contract' (Dresser, 1984).

PADs would develop the 'crisis card' concept. 'Crisis cards' have been generated by the user movement as an expression of patient autonomy: small enough to be carried in a wallet, they contain information about what individuals would like to happen if they are in a mental health crisis and apparently too ill to give an account of themselves. A crisis card would usually be drawn up without collaboration with the patient's treatment team, and express the patient's wishes. PADs would be intended by authors to be a binding expression of their treatment decisions.

A second aspect of PADs, one which might prove uncomfortable for mental health professionals, follows logically from the right of a competent adult to reject treatment, even if lifesaving. The competent sufferer from a psychiatric disorder could reject in advance treatment which is likely to alleviate his lliness, and perhaps save life. A less extreme exercise of the patient's wishes might be the cholce of a treatment less effective than others, or one which has significant resource implications (for example, requesting hospitalisation but refusing medication-which would shorten the episode - in favour of seclusion).

The use of living wills in psychiatric treatment has been sporadically debated in America (Szasz, 1982: Dresser, 1984; Rosensen \& Kasten, 1991; 
Rogers \& Centifanti, 1991; Perling, 1993) but not in Britain. In some states in the US, advance directives for psychiatric disorders are already possible (Oklahoma \& Oregon). New York and Massachusetts have laws authorising the appointment of health care proxies. While drafted with non-psychiatric patients in mind, they could be applied to patients with mental disorders (Appelbaum, 1991).

\section{Advantages of PADs}

We believe that PADs offer an opportunity for patients to be treated non-consensually, in hospital or in the community, while respecting their autonomy. A PAD respects the current emphasis on patient self-determination. Over the last few decades, patient autonomy has advanced at the expense of 'paternalism' or 'beneficence'. It is no longer assumed that a patient would agree with a physician's actions if only they were in a position to understand why these actions were being carried out. Patients have insisted on an increased say in their treatment and 'real' consent has received greater emphasis.

We consider that the option of a PAD, and the distinction between persons with and without capacity to make decisions, may offer a useful avenue for legislation appropriate to community treatment. PADs offer a means of reconciling autonomy and the initiation of non-consensual treatment at an early stage of relapse, a situation for which a 'community supervision order' has been sought but rejected (Royal College of Psychiatrists, 1993; House of Commons Select Committee, 1993).

PADs may also improve patient care by encouraging a dialogue between patients, carers and clinicians concerning the nature of the illness and the options for treatment. The House of Lords Select Committee on Medical Ethics stated the preparation of an advance directive "should stimulate discussion of . . . preferences between doctors and patients. They can assist the health-care team and other carers in making decisions about appropriate treatment". A PAD may be more effective in enabling the patient's views about care and treatment to be heard (due to its presence in the notes and the discussions that preceded it) than, for example, the Mental Health Act Code of Practice 1993.

\section{Challenges to implementation}

\section{Evaluating competence}

Whether PADs are viable depends largely on whether it is possible to evaluate competence (or capacity). Legislative provisions relating to compulsory treatment are presently almost exclusively about status - being detained under particular sections of the Mental Health Act 1983 permits non-consensual treatment. The functional concept of 'competence' plays a minor role. The PAD pushes the concept centre stage. However, evaluating competence is complex, not assisted at present by confusing legal tests.

PADs involve three competence-related decision points, concerning their (a) making; (b) applicability (loss of capacity 'triggering' the $\mathrm{PAD})$; and (c) revocation.

Making a psychiatric advance directive

Legal tests of competence are specific to a situation. In English law the test of capacity for making treatment decisions (and therefore an advance directive) is divided into three stages. A person must be capable of (a) comprehending and retaining relevant treatment information; (b) believing it; and (c) weighing it in the balance to arrive at a choice.

(a) Comprehending and retaining treatment information. A person must be able to understand, in broad terms, the nature, likely effects and risks of making an advance treatment decision, including the likelihood of any relevant treatment's success and any alternatives to it. Judging what facts a person needs to understand (the "relevant treatment information") is complicated in the case of a psychiatric illness because of the nature of mental illness. Suffcient understanding to make treatment decisions does not mean that a patient has to share entirely the medical view of his or her condition and treatment.

The $\operatorname{Re} C$ (1994) case sets the current legal standard. The court held that $C$, who was diagnosed as suffering from chronic paranoid schizophrenia, was competent to refuse a potentially life-saving amputation of a gangrenous leg. and that he could do so for the future by an advance directive. The presumption that $\mathrm{C}$ had the right of self-determination was not displaced by his severe mental illness. The judge decided that "although his general capacity is impaired by schizophrenia, it has not been established that he does not sufficiently understand the nature, purpose and effects of the treatment he refuses".

(b) Believing the treatment information. In $\operatorname{Re} C$ there was a difference in psychiatric opinion as to whether $C$ believed the relevant treatment information. In court, C "expressed complete confidence in his ability to survive his present trials" yet "he accepted the possibility of death as a consequence of retaining his limb". The judge concluded that although C's capacity was reduced by mental illness, there was no direct link between his delusions and his treatment decision, and that $C$ had "understood and retained the relevant treatment information, that 
in his own way he believes it, and that in the same fashion he has arrived at a clear choice".

(c) Weighing evidence and arriving at a choice: "the true choice test". The fact that a choice is contrary to what would be regarded as prudent by the majority of adults is only relevant if there are other reasons to doubt a person's capacity to decide $(\operatorname{Re} T, 1993)$. The courts in England and Wales have formed the view that certain conditions are capable of destroying a person's ability to make an informed choice, creating a compulsion to refuse treatment ( $R e W, 1992)$. In the case of $\operatorname{Re} K B(1994)$ it was held that a woman with anorexia nervosa was not able to make a 'true choice' to refuse feeding by naso-gastric tube because her refusal was held to be immediately related to her mental disorder (her disorder compelled her to refuse food), not, as with C's gangrenous leg, where the refusal related to a physical condition unconnected with his delusional beliefs.

The most recent decision on capacity was in $B$ $v$ Croydon Health Authority (1995) which points again to the need for clarification of the law. B was detained under the Mental Health Act, diagnosed as suffering from a psychopathic disorder, classified as borderline personality disorder. She had virtually stopped eating. The $\operatorname{Re} C$ three stage test of competence was applied but different conclusions as to B's capacity were reached in separate courts hearing the case. The Court of Appeal disagreed with the lower court's opinion that B had capacity, stating (obiter dictum) that at the critical time $B$ could not have made a true choice in refusing to eat, despite her intelligence and self-awareness. Their conclusion relied on B's statement that she found it difficult to believe the treatment information she was being given (that she might die without tube feeding) and that she was unable to break her routine of self-punishment (and therefore she was unable to make a "true choice").

In a recent report advocating a reform of the law relating to mental incapacity, the Law Commission (1995) has built on the $\operatorname{Re} C$ test but attempted to circumvent the difficult 'belief and 'true choice' elements. In their draft Mental Incapacity Bill, a person would be considered as without capacity if at the material time he or she is unable by reason of mental disability to make a decision for himself on the matter in question. This occurs if:

(a) he or she is unable to understand or retain the information relevant to the decision, including information about the reasonably foreseeable consequences of deciding one way or another or of failing to make a decision; or

(b) he or she is unable to make a decision based on that information.
The second arm (b) refers to whether the person's eventual decision is divorced from the ability to understand the relevant information. "A decision based on a compulsion, the overpowering will of a third party or any other inability to act on relevant information as a result of mental disability is not a decision made by a person with decision making capacity". The Law Commission also proposes that a person should not be regarded as unable to understand the information if he or she is able to understand an explanation "in broad terms and simple language", or is unable to make a decision by reason of mental disability "merely because he or she makes a decision which would not be made by a person of ordinary prudence".

The loss of competence triggering an advance directive: applicability

After a patient loses the capacity to make treatment decisions, the patient's advance directive would apply if the directive is sufficiently clear to cover the particular situation which has arisen. Difficulties may arise if unforeseen circumstances arise (e.g. a revolutionary new drug without the side-effects feared by the patient) or there might be dispute over whether the particular situation covered by the directive has indeed arisen. Previous experience of a recurrent mental illness with loss of capacity should make it easier to draft applicable instructions. An example might be "when I say I am Jesus, or when I say that I hear God's voice, my directive is to apply".

\section{Revocation of an advance directive}

The test of capacity for revoking an advance directive has not yet been considered by the English courts. The Law Commission comments that whether people have the capacity to alter their advance directives "is inevitably a question of fact and evidence in any particular case". In their earlier consultation paper they state that "if a patient is found incapable of understanding in broad terms what revocation involves, even when given the presumption of capacity, he should not be able to make an effective revocation". If the requisite capacity of revocation were to be less than that which was necessary to make the binding treatment decision, then a PAD might be revoked by a relapsing patient just at the point at which, when well, the person had previously considered it should be implemented.

We have considered the issue of competence in some detail since it is central to a PAD and the law is complex. But there is an important point to be made in relation to PADs in the situations we envisage. While there are difficulties with the concept of competence in general, we believe that recurrent psychotic episodes are more straightforward. Previous experience of precisely the 
same lllness and subsequent loss of capacity should make it easier to draft criteria highly specific to the individual and with the individual's endorsement.

Preventing coercion: signatories, witnesses and appeals

It would probably be in the interests of all parties for PADs to be witnessed by an independent psychiatrist who can attest to the competence of the maker, and for the maker to have access to an independent advocate. Cooperation between patients and clinicians would avoid the argument that a PAD was based on erroneous ideas or information, but the dangers of duress arising out of power inequalities should be recognised. Because of the possibility of coercion, an advocate should also witness the signing of a PAD, to attest to its making having been voluntary.

Appeals in cases of dispute

Because it will usually be the same clinician offering treatment and judging competence, unless there is an adequate mechanism to review cases where there is a doubt about the validity or applicability of the anticipatory decision, a PAD is not a means for a person to exercise autonomy. The Law Commission has proposed a judicial forum to which such cases could be referred. Another option would be independent ombudspersons set up by providers, offering a choice of forum. Meanwhile appeal could be made to the courts.

\section{Resource implications}

Drafting PADs would take time and therefore be costly to a treatment team if it is involved. The patient should be encouraged to have an advocate or solicitor, and then the question arises as to who should pay. Against this, the initiation of early treatment and the avoidance of hospital admission could lead to substantial savings. Limitations on what a service can offer, compared with the optimum, may be highlighted when patients consider what treatment they wish to have. A further issue which might arise is an insistence by the patient on a treatment which, although not entirely inappropriate, may be more costly than an alternative. For example. a patient might accept the need for hospitalisation against his will, but not medication which promises to shorten his hospital stay.

\section{Relationship to compulsory detention}

The Mental Health Act, as presently drafted, could override a PAD. Effective PADs will necessitate reform. The Law Commission believes the judiciary should not be able to override an advance directive, applicable in the circumstances, even when it is clearly contrary to the patient's best interests. We believe the use of compulsory treatment to override a PAD would similarly be wrong, except where there is a danger to others, when the public interest would legitimately require the use of compulsion. A patient's rejection of certain treatments, if it would lead to that person becoming a danger to others, should in our view continue to be overridden. One way of dealing with the issue of potential dangerousness to others would be for an author to address this situation explicitly in a PAD, making it clear that under such circumstances treatment would be acceptable. Provided a PAD is made voluntarily, we do not think consent to such future treatment should be ineffective.

\section{Conclusions}

Many have argued that the time has come for a review of this country's mental health legislation. Legislation needs to support and encourage the capacity of individuals to make their own decisions, set out rights to appropriate care and provide effective safeguards for patients and the community. The role of PADs should be considered as part of a framework for such reform. The decision to make a PAD would of course be voluntary. Compulsory treatment provisions would operate as before for those not wishing to make a directive. We cannot tell how many patients might elect to take up a PAD option, but we suggest that it offers an ethically sound approach to reconciling self-determination and early non-consensual treatment.

\section{References}

APpelbaum, P. S. (1991) Advance directives for psychiatric treatment. Hospital and Community Psychiatry. 49. 983-984.

- \& Grisso, T. (1995) The MacArthur Treatment Competence Study: I. Mental illness and competence to consent to treatment. Law and Human Behaviour. 19. 105-126.

DePartment OF Health AND THE Welsh OFfice (1993) Mental Health Act Code of Practice (2nd edn). London: HMSO.

DRESSER, R. (1984) Bound to treatment: the Ulyses Contract. Hastings Center Report, 14, 13-16.

House of COMmons SELECT COMMrTEE (1993) Health Committee Fyth Report, Community Supervision Orders. London: HMSO.

LAw Comassion (1995) Mental Incapacty. No. 231. London: HMSO.

PERuNG, L. J. (1993) Health care advance directives: implications for Florida mental health patients. Universty of Miami Law Review, 48, 193-228.

ROGERS, J. A. \& CENTIFANT, J. B. (1991) Beyond 'selfpaternalism': a response to Rosenson and Kasten. Schizophrenia Bulletin. 17, 9-14. 
Rosensen, M. K. \& KASTEN, A. M. (1991) Another view of autonomy: arranging for consent in advance. Schizophrenia Bulletin, 17, 1-7.

ROYAL COLLEGE OF PSYCHIATRISTS (1993) Community Supervision Orders: Discussion Document. London: Royal College of Psychiatrists.

Szasz, T. S. (1982) The psychiatric will: a new mechanism for protecting persons against "psychosis" and psychiatry. American Psychologist, 37, 762-770.

\section{Law reports}

B v CROYDON HEALTH AUTHORTY [1995] 1 All ER683.

RE C (Adult: Refusal of Treatment) [1994] 1 WLR290.
RE KB [1994] Unreported case of 28th January 1994 before Mr Justice Ewbank.

RE T (Adult: refusal of medical treatment) [1993] FAM 95.

RE W (A Minor) (Consent to Medical Treatment) [1992] 3 WLR758, 769.

Adina Halpern, Nightingale Fellow in Mental Health Law, Trinity Hall, Cambridge CB2 1TJ; and *George Szmukler, Consultant Psychiatrist, Bethlem and Maudsley NHS Trust, Maudsley Hospital, Denmark Hill, London SE5 8AZ

*Correspondence 